\title{
Enhanced lignin biodegradation by consortium of white rot fungi: microbial synergistic effects and product mapping
}

Tangwu Cui ${ }^{1 \dagger}$, Bo Yuan ${ }^{1 \dagger}$, Haiwei Guo ${ }^{2}$, Hua Tian ${ }^{3}$, Weimin Wang ${ }^{1}$, Yingqun Ma' ${ }^{1}$ Changzhi Li ${ }^{2 *}$ and Qiang Fei ${ }^{1,4^{*}}$

\begin{abstract}
Background: As one of the major components of lignocellulosic biomass, lignin has been considered as the most abundant renewable aromatic feedstock in the world. Comparing with thermal or catalytic strategies for lignin degradation, biological conversion is a promising approach featuring with mild conditions and diversity, and has received great attention nowadays.
\end{abstract}

Results: In this study, a consortium of white rot fungi composed of Lenzites betulina and Trametes versicolor was employed to enhance the ligninolytic enzyme activity of laccase (Lac) and manganese peroxidase (MnP) under microbial synergism. The maximum enzymatic activity of Lac and MnP was individually $18.06 \mathrm{U} \mathrm{mL}^{-1}$ and $13.58 \mathrm{U}$ $\mathrm{mL}^{-1}$ along with a lignin degradation rate of $50 \%$ (wt/wt), which were achieved from batch cultivation of the consortium. The activities of Lac and MnP obtained from the consortium were both improved more than $40 \%$, as compared with monocultures of L. betulina or T. versicolor under the same culture condition. The enhanced biodegradation performance was in accordance with the results observed from scanning electron microscope (SEM) of lignin samples before and after biodegradation, and secondary-ion mass spectrometry (SIMS). Finally, the analysis of heteronuclear single quantum coherence (HSQC) NMR and gas chromatography-mass spectrometry (GC-MS) provided a comprehensive product mapping of the lignin biodegradation, suggesting that the lignin has undergone depolymerization of the macromolecules, side-chain cleavage, and aromatic ring-opening reactions.

Conclusions: Our results revealed a considerable escalation on the enzymatic activity obtained in a short period from the cultivation of the L. betulina or T. versicolor due to the enhanced microbial synergistic effects, providing a potential bioconversion route for lignin utilization.

Keywords: White rot fungi (WRF), Lignin biodegradation, Laccase, Manganese peroxidase, Synergistic effect, Product mapping

*Correspondence: licz@dicp.ac.cn; feiqiang@xjtu.edu.cn

†Tangwu Cui and Bo Yuan are contributed equally to this work.

${ }^{1}$ School of Chemical Engineering and Technology, Xi'an Jiaotong

University, Xi'an 710049, China

${ }^{2}$ CAS Key Laboratory of Science and Technology On Applied Catalysis,

Dalian Institute of Chemical Physics, Chinese Academy of Sciences, 457

Zhongshan Road, Dalian 116023, People's Republic of China

Full list of author information is available at the end of the article

\section{Background}

As the major component of lignocellulose, lignin has drawn great attention due to its aromatic structure characteristic that mainly composed of three phenylpropane units (i.e., sinapyl alcohol, coniferyl alcohol, and $p$-coumaryl alcohol). The utilization of lignin can be divided into the following two ways: direct application as soil amendments and pesticide sustained-release agents, or be used as a feedstock for the production of phenols and other high-value compounds [1]. The degradation 
of lignin into small molecules is still a challenge due to the complexity of linkages and recalcitrance by various bonds $[2,3]$. Therefore, it is critical to explore efficient approaches to degrade lignin polymer via physical, chemical or biological routes [4]. As an example for funneling the mixture of monomers by chemo-catalytic methods to produce value-added products, in 2020, Liao et al. reported a biorefinery process that converts $78 \mathrm{wt} \%$ birch into xylochemicals, which represents one of the major breakthrough towards full utilization of lignin $[5,6]$. In recent years, great efforts have been made on lignin biodegradation due to its mild condition, diversified choices of microorganisms, and high oxidative potentials. Mechanisms of the lignin degradation by major ligninolytic enzymes including laccase (Lac), manganese peroxidase $(\mathrm{MnP})$, and lignin peroxidase (LiP) have been extensively studied. Among them, Lac is a polyphenol oxidase that is restricted to some lignin phenolic substrates due to its relatively low redox potential. The glycosylated heme protein MnP secreted by white-rot fungi was one of the most effective lignin degradation peroxidase [7]. The most common bonds in lignin including $\beta-O-4, \beta-\beta$, $4-O-5$, and $5-5^{\prime}$ have all been found to be cleaved by biodegradation methods [8-11].

White rot fungi (WRF) plays an important role in biodegradation of lignin [12] and the catabolism in WRF have been thoroughly investigated in previous studies [13-15], of which the $\beta$-ketoadipate ( $\beta$-KA) pathway has been identified as one of the most common pathways for biodegradation of lignin [16]. The products frequently derived from the process include monophenols, benzenediol derivatives, aromatic hydrocarbons, short-chain acids, etc. [17, 18]. Lenzites betulina and Trametes versicolor are two common WRF that can effectively secrete Lac and/or MnP to depolymerize lignin into small molecules $[14,19-23]$. Although extensive studies of these two WRF have been carried out to investigate enzymes, mechanisms, and pathways of lignin biodegradation, to the best of our knowledgement, most of the reports only focus on monoculture of these fungus, which greatly limits the degradation rates of the bioconversion of lignin. On the other hand, lignin degradation by a consortium of fungi or bacteria has shown certain advantages in terms of improved enzymatic activities, novel secondary metabolites, better substrate utilization, higher enzyme diversity, etc. [24-26].

On the purpose of enhancing lignin biodegradation efficiency, studying the synergistic effects of fungi, and mapping the products from the degradation process [27, 28], herein a consortium of WRF composed of L. betulina and $T$. versicolor was investigated in batch cultures with lab-optimized medium. The enzymatic activities of two important ligninolytic enzymes ( $\mathrm{Lac}$ and $\mathrm{MnP}$ ) secreted by the WRF consortium were examined throughout the cultivation. The performance of lignin biodegradation was determined by calculating the degradation rates and running the scanning electron microscope (SEM) and secondary-ion mass spectrometry (SIMS). Furthermore, detailed product mapping was analyzed by employing heteronuclear single quantum coherence (HSQC) NMR and gas chromatography-mass spectrometry (GC-MS). Finally, a plausible degradation process via the catabolic pathways during the co-culture of L. betulina and T. versicolor was proposed based on experimental results.

\section{Results and discussion}

\section{Synergistic effects of WRF consortium on ligninolytic enzyme activity and biodegradation}

The induction of ligninolytic enzymes was shown to be stimulated when culturing a consortium of WRF due to interspecific interactions [29-32]. Therefore, to investigate the synergistic influence of the WRF consortium on lignin biodegradation, enzymatic activities were analyzed daily during the cultivation with or without the supplement of lignin. As shown in Fig. 1, the highest enzymatic activities of $\mathrm{Lac}\left(18.06 \mathrm{U} \mathrm{mL}^{-1}\right)$ and $\mathrm{MnP}\left(13.58 \mathrm{U} \mathrm{mL}^{-1}\right)$ were achieved in the cultures in the presence of lignin, which reduced the produce time of ligninolytic enzymes over $30 \%$. This finding may be explained that the interspecific interactions between WRFs accelerate a fungal metabolic switch of the formation from primary to secondary metabolites that stimulates the secretion of ligninolytic enzymes [33, 34]. It was believed that ligninolytic enzymes may be regulated differently at the interface of interspecific interactions in response to various stressful conditions. It has been reported that the competition of nutrients or the production of free radicals such as reactive oxidative species (ROS) derived from oxidative stress could cause stimulation to enzymatic inductions [35].

To have a comprehensive understanding on the advantages of consortium culture, the activities of Lac and $\mathrm{MnP}$ obtained in cocultures were compared with monocultures of $L$. betulina and $T$. versicolor. As shown in Fig. 2, the enzyme activities from cocultures were more than $40 \%$ higher than the sum of the values observed in mono-cultivation, mainly attributed to the fact that cocultivation of interacting fungi elevates expressions of $\mathrm{Lac}$ and $\mathrm{MnP}$ as well as the induction of novel isozymes. Ligninolytic enzymes such as Lac and LiP could be enhanced to mediate the stress and remove the ROS [32], which were approved by investigating the metabolites at the interaction zones, where novel metabolites were released in response to antagonistic interactions. It was obvious that the enzyme activities for both Lac and MnP obtained in the consortium cultures were higher than most of the previous reports with either monocultures or 


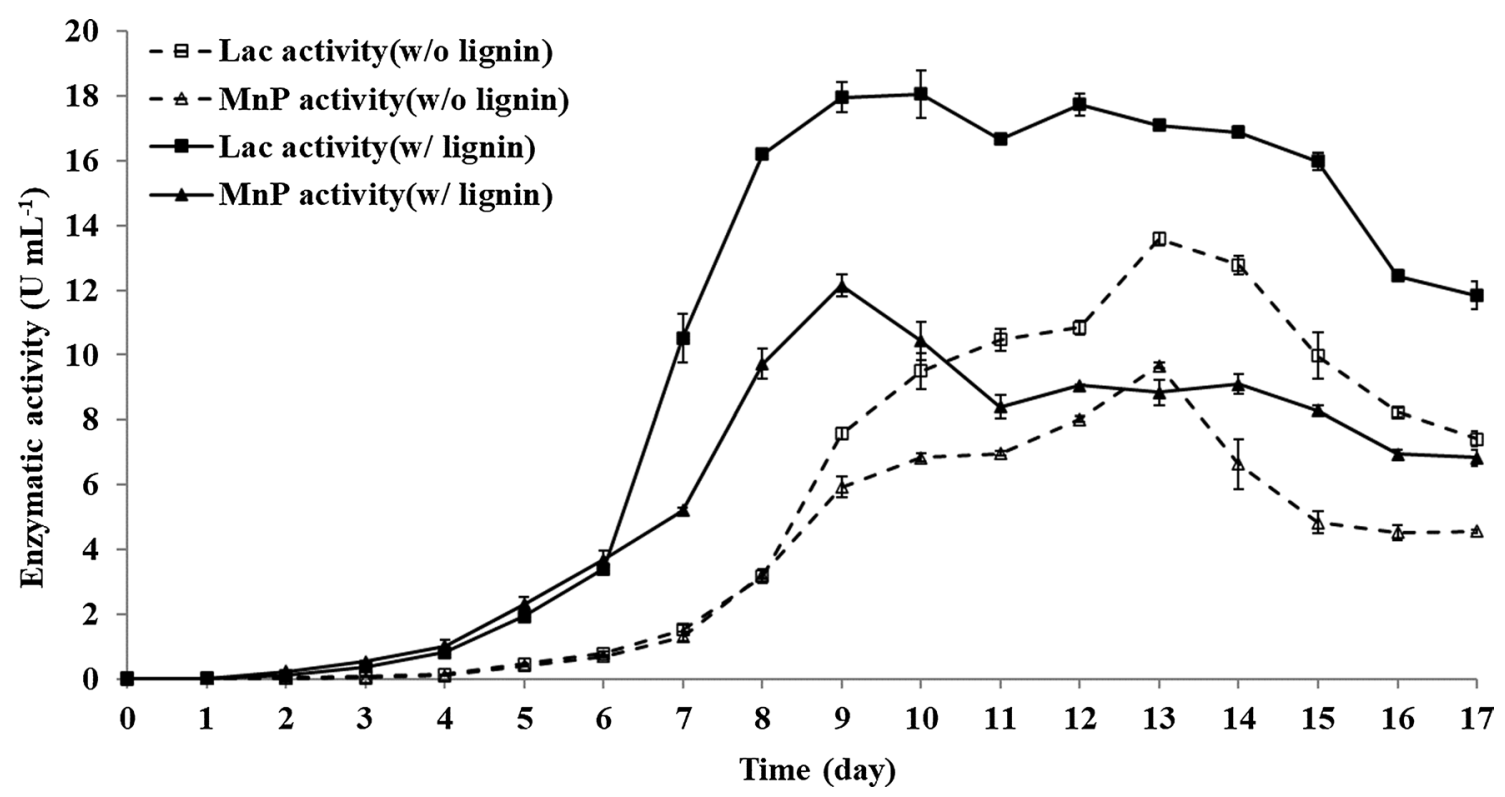

Fig. 1 Time courses of Lac and MnP enzymatic activities in the culture of consortium. Dot lines present the cultures without adding lignin; solid lines present the cultures with adding lignin
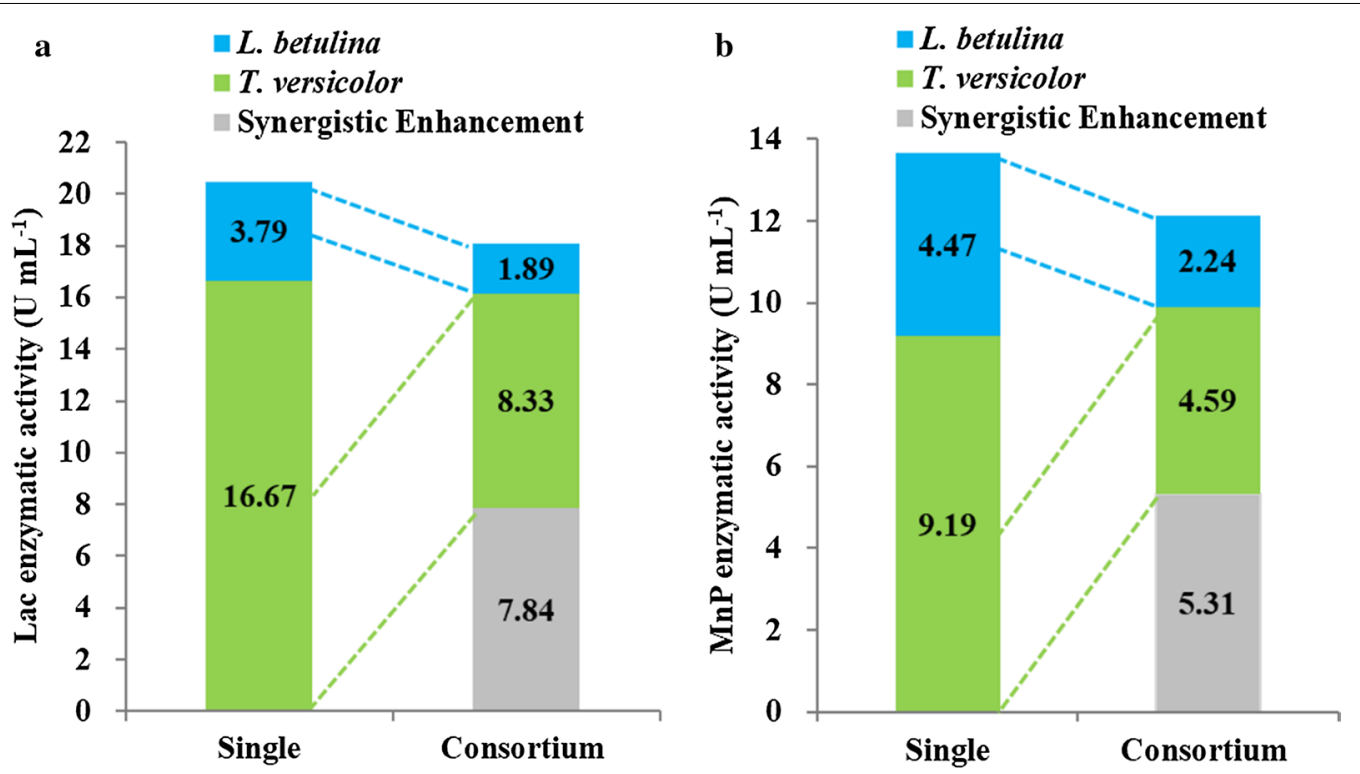

Fig. 2 Enhanced synergistic effects on enzymatic activities of Lac (a) and MnP (b)

cocultures (Table 1), indicating an enhanced synergistic effect of the combination of L. betulina or T. versicolor, which promoted the inductions of ligninolytic enzymes. Nevertheless, the exact synergistic mechanisms of the paired WRFs need to be elucidated with more research data.

Based on the enzymatic activities data under interspecific interactions, the influence of improved enzymatic activities on degradation products was studied. The results of degradation rates, in combination with SEM and SIMS results provided more insights into the biodegradation process. The lignin degradation rate of the consortium was determined to be $50 \%(\mathrm{wt} / \mathrm{wt})$, which was much higher not only than that from the cultures of $L$. betulina (26.6\%) and T. versicolor (37.2\%), but also than previous reports with consortium of $34.1 \%$ (wt/wt) by 
Table 1 Maximum enzymatic activities for Lac and MnP

\begin{tabular}{|c|c|c|c|}
\hline Microorganism & Lac, $\mathrm{U} \mathrm{mL}^{-1}$ & $\mathrm{MnP}, \mathrm{U} \mathrm{mL}^{-1}$ & References \\
\hline L. betulina & 0.026 & 0.03 & [19] \\
\hline L. betulina & 0.127 & 0.039 & [20] \\
\hline T. versicolor & 0.525 & 0.107 & [20] \\
\hline T. versicolor & 0.37 & 0.0039 & [21] \\
\hline T. versicolor & 0.159 & 0.109 & [22] \\
\hline Inonotus obliquus & - & 159.0 & {$[15]$} \\
\hline Consortium of Trametes sp. AH28-2 and Trichoderma sp. ZH1 & 6.210 & - & [32] \\
\hline $\begin{array}{l}\text { Consortium of P. chrysosporium, T. versicolor, Aspergillus niger, Penicillium chrysogenum, Tricho- } \\
\text { derma harzianum, and P. citrinum }\end{array}$ & - & 66.70 & [36] \\
\hline Consortium of Rhodotorula mucilaginosa and Pleurotus ferulae JM301 & 10.58 & - & [37] \\
\hline Consortium of Phanerochaete chrysosporium Burdsall and Trichoderma reesei RUT-C30 & $<0.6$ & 2.39 & [38] \\
\hline Consortium of L. betulina and T. versicolor & 18.06 & 13.58 & This study \\
\hline
\end{tabular}

Dichomitus squalens [39] or $28.37 \%$ (wt/wt) by microbial consortia [40]. Subsequently, SEM was performed on the purpose of identifying correlation of surface morphology with biodegradation (Fig. 3). The lignin after treatment by the consortium (Fig. 3c) showed that the particle size of lignin was reduced significantly to below $4 \mu \mathrm{m}$, which was smaller than the control sample (Fig. 3a) and the one incubated without microorganisms (Fig. 3b). In addition, more irregular fragments are observed in Fig. 3c, and the particles were more densely packed. This result was consistent with the report by Zhu et al. [41], in which a decrease in particle size was observed on lignin sample treated by Bacillus ligniniphilus.

\section{Product mapping of the lignin biodegradation by WRF consortium}

The degradation samples were analyzed with the aim to reveal the change of molecular weights of the products by SIMS, a state-of-art technique to analyze the topmost surface of the sample, which has shown immense potential for applications in various fields. The heterogeneous nature of lignin has evidently limited its solubility without pretreatment. However, pretreatment often leads to a certain degree of bond breakage in lignin sample, causing inaccuracies in the data to the original sample. SIMS resolved the above issues, since it was performed on solid samples, and gas cluster ion beam (GCIB) minimized the damage to lignin samples. In addition, the high energy GCIB employed offered chemical map of the sample surface at the spatial resolution of 1 micron. Figure 4 shows the SIMS spectra of the lignin sample before (control sample) and after the cultivation of the consortium with adding lignin. The signal intensities of the monomers at $\mathrm{m} / \mathrm{z} 260$ were approximately 5 times higher in the control sample than in the treated sample, indicating the cleavage of the linkages between the primary aromatic units after degradation. Many signals emerged for the sample after cultivation, ranging from approximately m/z 150 to 450 , confirming that lignin macromolecules have been degraded into smaller fragments. From the above data, conclusions can be made that the consortium contributed to the improvement of the enzymatic activities and successful biodegradation based upon synergistic effects. Therefore, details of the products and possible pathways and mechanisms were explored by the following analyses.

The product mapping was conducted by HSQC and GC-MS, which provided a full picture of the products generated from the biodegradation of lignin and showed potential metabolic pathways and mechanisms. The structures of lignin analyzed by HSQC are shown in Fig. 5. The spectra of the control sample (Fig. $5 \mathrm{a}, \mathrm{\delta C} /$ $\delta \mathrm{H} 50-140 / 2.0-9.0)$ could be divided into aromatic rings $(\delta \mathrm{C} / \delta \mathrm{H} 90-140 / 6.0-9.0)$ and side chain regions $(\delta \mathrm{C} / \delta \mathrm{H}$ 50-90/2.0-6.0). The region for aromatic rings showed multiple signals for C $\alpha$-oxidized syringyl ( $\left.\mathrm{S}^{\prime}\right), p$-hydroxyphenyl $(\mathrm{H})$, guaiacyl $(\mathrm{G})$, and syringyl (S) structures, which were the outcome of the natural route for lignin degradation cleaved by Lac and $\mathrm{MnP}$ [42]. The region for side chains showed methoxy (OMe) and $\beta-O-4$ structures $(\mathrm{A} \gamma)$ and the solvent signal was assigned to Pyridine. Compared with the control sample, the signals for $S$ and $S$ ' structures in the aromatic ring region and $A \gamma$ structures in the side chain region diminished (Fig. 5b). In addition, less signals for $\mathrm{G}$ and $\mathrm{H}$ moieties in the aromatic ring region and $\mathrm{OMe}$ moieties in the side chain regions were identified. Our findings are in a good agreement with previous literatures, where Lac was found to be responsible for the released aromatic subunits of lignin during biodegradation [42].

The signals at $c a$. $(\delta \mathrm{C} / \delta \mathrm{H} \quad 68-70 / 3.0-3.5)$ might be attributed to WRF consortium residue structure. The above results indicated that the fungi consortium 

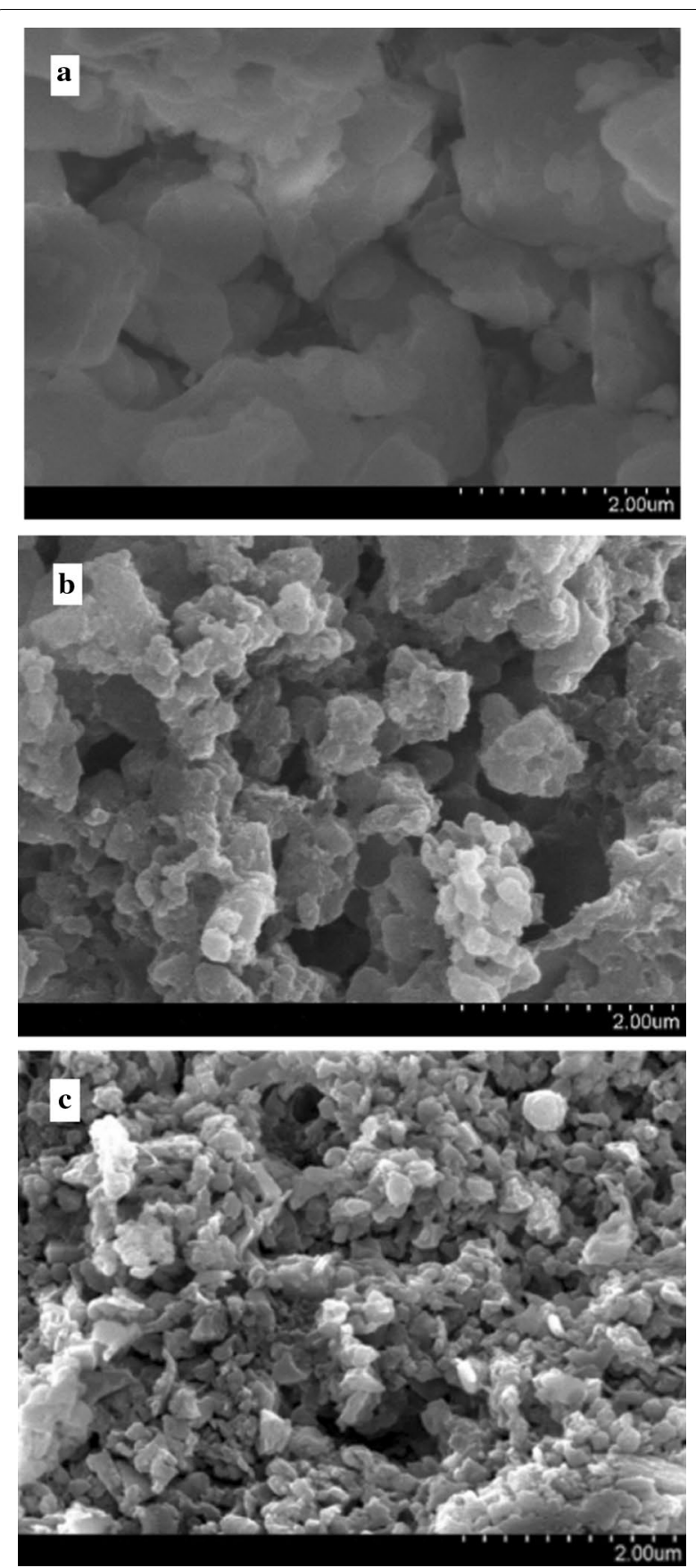

Fig. 3 SEM images for comparisons of lignin samples before and after biodegradation. a Control sample; $\mathbf{b}$ lignin sample (with no microorganisms); c lignin sample from the consortium

preferentially removed the $\mathrm{S}$ moieties and underwent $\beta-\mathrm{O}-4$ bonds breakage and cleavage of the aromatic rings, thereby depolymerizing lignin to produce small molecular products. The results for reduction of $\mathrm{OMe}$ groups and $\beta-5$ bonds breakage were in agreement with the report from Mao et al. [43]. In addition, Zhao et al. also reported an enzymatic and microbial synergistic degradation of lignin, and results also showed that $\beta-O-4$ subunits were preferentially removed [44]. These results suggested several possible mechanisms for lignin degradation, and will be further discussed with GC-MS results.

Products from lignin biodegradation were identified and characterized by GC-MS (Table 2). These products can be categorized into three groups including substituted aromatics, small molecule acids and aliphatic acids. First, substituted aromatics are side-chain cleavage products, which are also demonstrated by HSQC results. For example, 4-methylcinnamic acid (Table 2, Entry 21) came from degradation of coumaryl alcohol [45]. Second, $p$-hydroxybenzoic acid (Table 2, Entry 16) is a key intermediate of protocatechuic acid, both are typical intermediates in the protocatechuate branch pathway, and can be further metabolized via the $\beta$-KA pathway [45]. Similarly, benzoic acid (Table 2, Entry 4) came from degradation of cinnamic acid that leads to catechol, which is a key intermediate for the catechol branch of the pathway that goes into $\beta$-KA pathway [46]. Finally, oxalic acid, succinic acid, maleic acid, and other small acids were probably generated from ring opening via the ortho or meta oxidative ring fission $[47,48]$, which was in the agreement with the HSQC data, where the aromatic regions diminished after treatment. A final example is adipic acid (Table 2, Entry 13) [49] as a valuable dicarboxylic acid derived from muconic acid, which comes from the catechol ortho degradation pathway. In conclusion, the GC-MS data showed key intermediates for the side-chain fission and ring-opening, indicating that the $\beta$-KA pathway should be the main pathway for the lignin degradation. In addition, the upper funneling pathways including protocatechuate pathway and catechol pathway also possibly existed in the biodegradation system by the consortium.

\section{Conclusions}

Lignin biodegradation by fungi consortiums shows great potential to overcome the bottlenecks of one single microorganism-catalyzed lignin degradation with regard to the low enzymatic activity, low enzyme diversity, and limited substrate scope. In this study, a considerable escalation on the ligninolytic enzymatic activities including Lac $\left(18.06 \mathrm{U} \mathrm{mL}^{-1}\right)$ and $\mathrm{MnP}(13.58$ $\mathrm{U} \mathrm{mL} \mathrm{m}^{-1}$ ) were obtained in a $30 \%$ shorten producing period from the cultivation of the WRF consortium relying on the microbial synergistic effects. These findings were confirmed by analyzing the surface morphology and molecular weights of the products by SEM and SIMS. Notably, the lignin degradation rate of the consortium was $40 \%$ higher than that from monocultures 

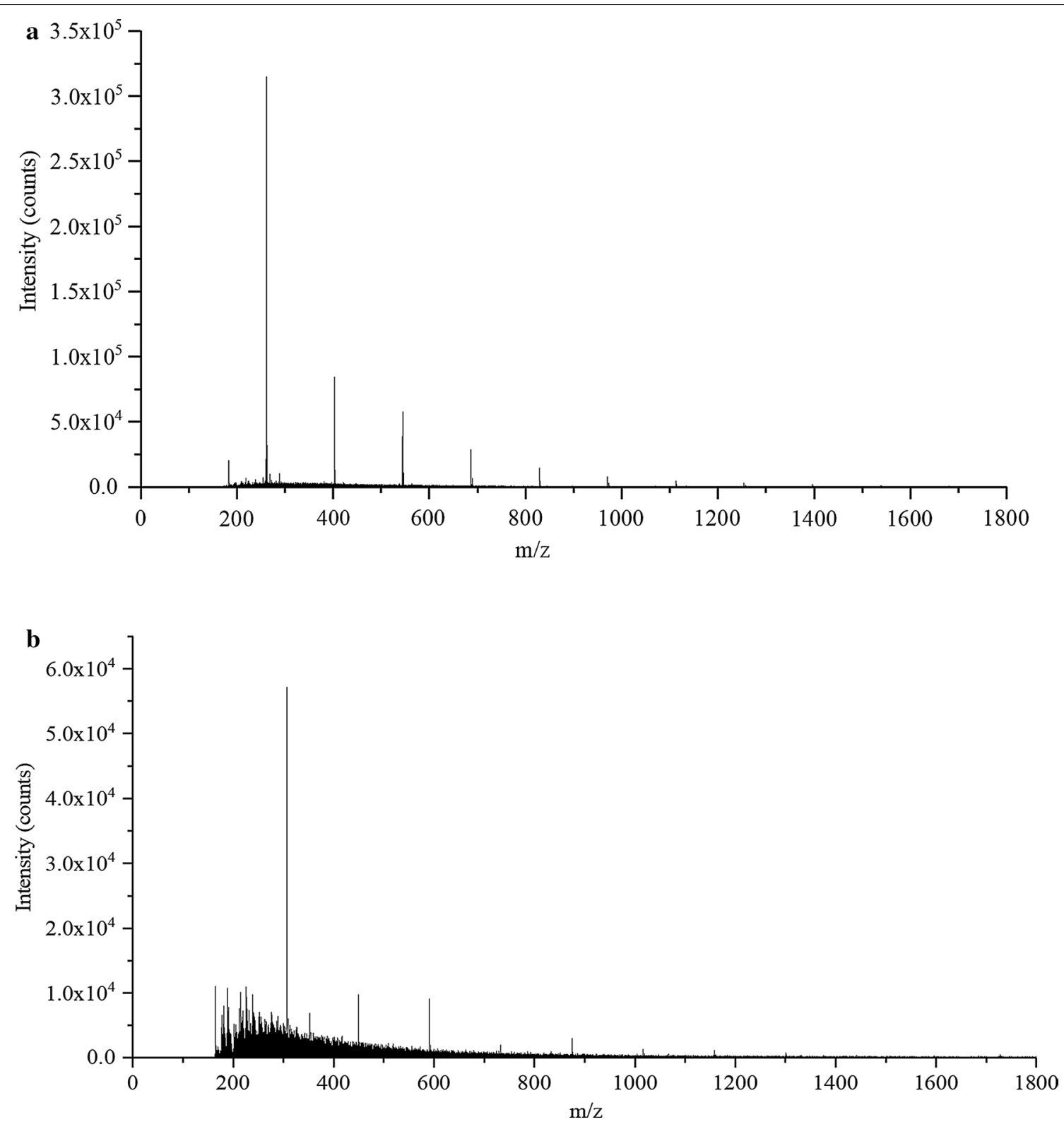

Fig. 4 SIMS analysis of lignin for molecular weights comparisons. a Control sample; b lignin sample from the consortium

of L. betulina and T. versicolor. Moreover, 2D-HSQC NMR spectra exhibited the bond cleavage and diminish of the functional groups. Finally, the product mapping was identified by GC-MS and the possible pathway for lignin degradation was discussed. The present study provides an advantageous method for lignin biological treatment. Future research will focus on exploring the molecular mechanism of the synergistic effect of these fungi consortiums as well as converting lignin into value-added chemicals through the developed biological strategy.

\section{Materials and methods}

\section{Microorganisms and culture conditions}

The L. betulina and T. versicolor were purchased from China General Microbiological Culture Collection Center (CGMCC). These WRFs were maintained on potato dextrose agar (PDA) plates by a monthly subculture. The lab-modified culture medium ( $\mathrm{pH}$ 5.4) used 


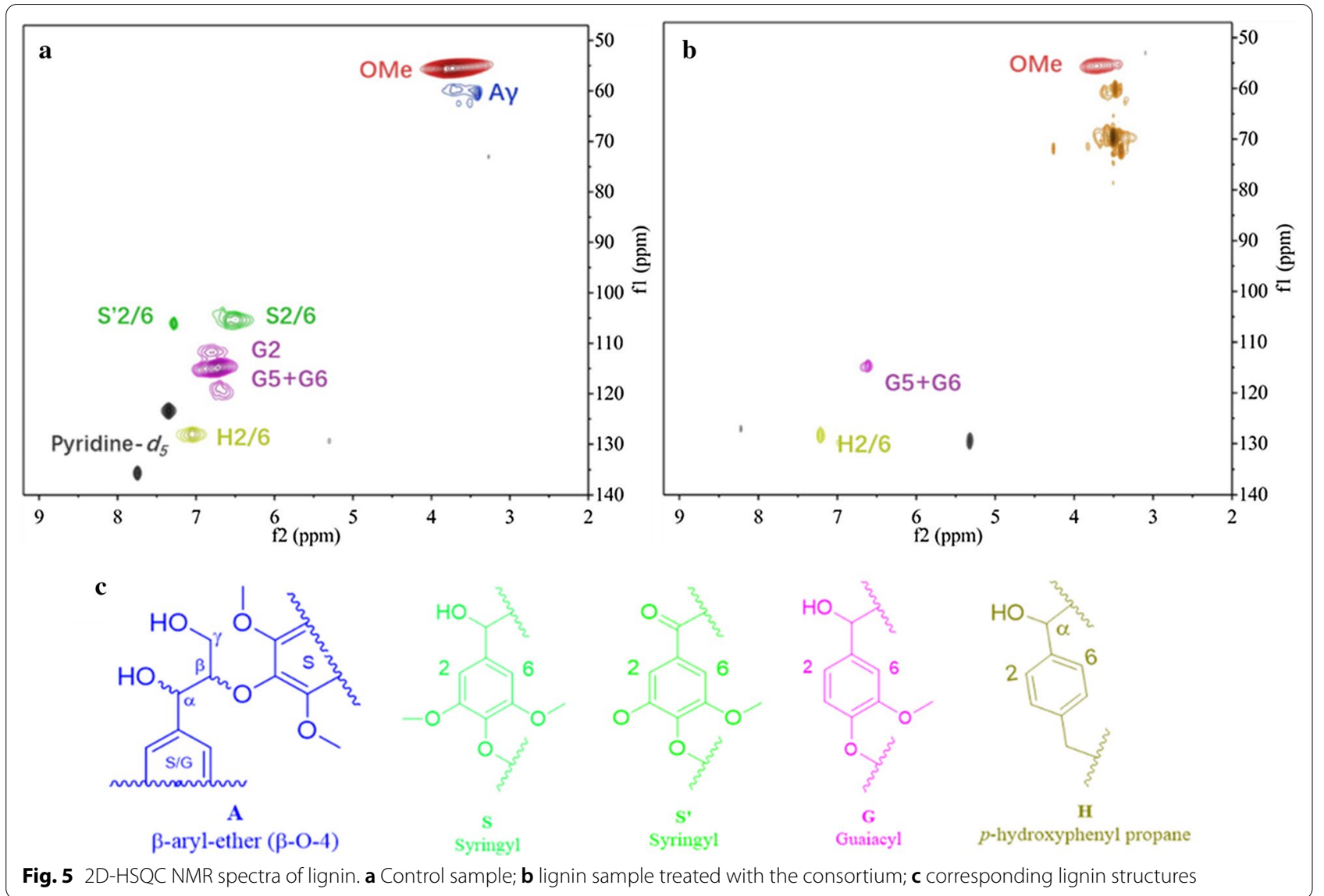

for all experiments consists of glucose $\left(20 \mathrm{~g} \mathrm{~L}^{-1}\right)$, peptone $\left(5 \mathrm{~g} \mathrm{~L}^{-1}\right)$, yeast extract powder $\left(2 \mathrm{~g} \mathrm{~L}^{-1}\right), \mathrm{KH}_{2} \mathrm{PO}_{4}$ $\left(2 \mathrm{~g} \mathrm{~L}^{-1}\right), \mathrm{MgSO}_{4} 7 \mathrm{H}_{2} \mathrm{O}\left(0.5 \mathrm{~g} \mathrm{~L}^{-1}\right), \mathrm{MnSO}_{4}(0.5 \mathrm{mM})$, $\mathrm{CaCl}_{2} 2 \mathrm{H}_{2} \mathrm{O}\left(0.1 \mathrm{~g} \mathrm{~L}^{-1}\right)$, succinic acid $\left(1.18 \mathrm{~g} \mathrm{~L}^{-1}\right)$, ammonium tartrate $\left(1.84 \mathrm{~g} \mathrm{~L}^{-1}\right)$, thiamine $\left(1 \mathrm{mg} \mathrm{L}^{-1}\right)$, tween$80\left(0.5 \mathrm{~mL} \mathrm{~L}^{-1}\right)$, trace element $\left(70 \mathrm{~mL} \mathrm{~L}^{-1}\right)[50,51]$. The trace element components consist of $\mathrm{MgSO}_{4} 7 \mathrm{H}_{2} \mathrm{O}(3 \mathrm{~g}$ $\left.\mathrm{L}^{-1}\right), \mathrm{MnSO}_{4} \mathrm{H}_{2} \mathrm{O}\left(0.5 \mathrm{~g} \mathrm{~L}^{-1}\right), \mathrm{NaCl}\left(1.0 \mathrm{~g} \mathrm{~L}^{-1}\right), \mathrm{FeSO}_{4}$ $7 \mathrm{H}_{2} \mathrm{O}\left(0.1 \mathrm{~g} \mathrm{~L}^{-1}\right), \mathrm{CoCl}\left(0.1 \mathrm{~g} \mathrm{~L}^{-1}\right), \mathrm{ZnSO}_{4} 7 \mathrm{H}_{2} \mathrm{O}(0.1 \mathrm{~g}$ $\left.\mathrm{L}^{-1}\right), \mathrm{CuSO}_{4} 5 \mathrm{H}_{2} \mathrm{O}\left(0.1 \mathrm{~g} \mathrm{~L}^{-1}\right), \mathrm{KAl}\left(\mathrm{SO}_{4}\right)_{2} 12 \mathrm{H}_{2} \mathrm{O}(0.01 \mathrm{~g}$ $\left.\mathrm{L}^{-1}\right), \mathrm{H}_{3} \mathrm{BO}_{3}\left(0.01 \mathrm{~g} \mathrm{~L}^{-1}\right), \mathrm{NaMo}_{4} 2 \mathrm{H}_{2} \mathrm{O}\left(0.01 \mathrm{~g} \mathrm{~L}^{-1}\right)$. The glass beans (id. $0.5 \mathrm{~cm}$ ) were applied in all liquid cultures for WRF growth. The other chemicals were used without further purification unless otherwise stated. Lignin used in this study was pure sample without containing any cellulosic and hemicellulosic components, which was provided by Shandong Longlive Bio-Technology Co., Ltd. It belongs to industry alkaline lignin that was extracted from corn stalk. In detail, the raw corn stalk material $(70 \mathrm{~g})$ was first treated with $1 \mathrm{M} \mathrm{NaOH}$ at $50{ }^{\circ} \mathrm{C}$ for $3 \mathrm{~h}$ with the solid/liquid ratio of $1: 20(\mathrm{~g} / \mathrm{ml})$. After reaction, the filtrated liquid fraction was adjusted to $\mathrm{pH} 5-6$ with $6 \mathrm{M} \mathrm{HCl}$, and were then concentrated and precipitated in ethanol to remove hemicellulosic component. The aqueous ethanol filtrate containing lignin was concentrated under vacuum and reprecipitated by acidification with $6 \mathrm{M} \mathrm{HCl}$ to $\mathrm{pH}$ 2.0. Finally, the purified lignin was collected in $3.2 \mathrm{~g}$ after being dried at $50^{\circ} \mathrm{C}$ in vacuum oven.

A loop of colonies of both strains from PDA plates was transferred in $250 \mathrm{~mL}$ flasks for seed cultures for 168$192 \mathrm{hs}$. A $10 \%$ (vol/vol) inoculum was used for all experiments using $1000 \mathrm{~mL}$ flasks containing $600 \mathrm{~mL}$ medium. The seed solutions of L. betulina and T. versicolor of $6 \mathrm{~mL}$ were inoculated into the culture media. The inoculation solution of the consortium was made up of $3 \mathrm{~mL}$ of L. betulina and $3 \mathrm{~mL}$ of $T$. versicolor. Lignin of $1 \%(\mathrm{wt} /$ vol) was added into the culture media to study the effect of lignin supplement on WRF growth. All the cultures were performed at $30{ }^{\circ} \mathrm{C}$ and $200 \mathrm{rpm}$ in a rotary shaker (ZQZY-70CS, Zhichu, China) with triplicates.

\section{Enzymatic activity assays}

Ligninolytic enzymatic activity assays were performed everyday using a UV spectrophotometer (Persee TU-1800, Beijing, China) in this study. The supernatant was collected from $1 \mathrm{~mL}$ culture solution after 
Table 2 Lignin degradation products identified by GC-MS

\begin{tabular}{|c|c|c|c|c|}
\hline Entry & Retention time (min) & Product Name & Product Structure & $\mathrm{m} / \mathrm{z}$ \\
\hline 1 & 12.5 & Oxalic acid (ethanedioic acid) & & 90 \\
\hline 2 & 12.7 & 3-Methyl-1.3-butanediol & & 104 \\
\hline 3 & 13.7 & 2-Methyl-3-hydroxybutyric acid & & 118 \\
\hline 4 & 14.3 & Benzoic acid & & 122 \\
\hline 5 & 15.1 & Phenylacetic acid & & 136 \\
\hline 6 & 15.2 & Maleic acid & & 116 \\
\hline 7 & 15.3 & Succinic acid & & 118 \\
\hline 8 & 15.8 & Fumaric acid & & 116 \\
\hline 9 & 16.6 & Glutaric acid & & 132 \\
\hline 10 & 17.1 & $\alpha$-Hydroxyphenylacetic acid & & 152 \\
\hline 11 & 17.3 & 4-Hydroxyvaleric acid & & 118 \\
\hline 12 & 17.8 & 2-Hydroxybutanedioic acid & & 134 \\
\hline 13 & 17.9 & Adipic acid & & 146 \\
\hline 14 & 18.7 & 2.3-Dihydroxybutanedioic acid & & 150 \\
\hline 15 & 18.9 & 2-Hydroxyglutaric acid & & 148 \\
\hline 16 & 19.5 & p-Hydroxybenzoic acid & & 138 \\
\hline 17 & 20.9 & 1,2,3-Propenetricarboxylic acid & & 174 \\
\hline 18 & 21.0 & $\begin{array}{l}\text { 2-Hydroxy-5-methoxybenzoic } \\
\text { acid }\end{array}$ & & 168 \\
\hline 19 & 21.9 & 2-tert-Butyl-6-methylphenol & & 164 \\
\hline 20 & 23.9 & Hexadecanoic acid & & 256 \\
\hline 21 & 24.6 & 4-Methylcinnamic acid & & 162 \\
\hline 22 & 25.5 & 9-Octadecenoic acid & & 282 \\
\hline 23 & 27.7 & $\begin{array}{l}\text { 2.6-Di-tert-butyl-4-methoxy- } \\
\text { phenol }\end{array}$ & & 236 \\
\hline
\end{tabular}

centrifugation at $8000 \mathrm{rpm}$ for $10 \mathrm{~min}$ to remove the cells and residual lignin. Lac activity was determined by monitoring the reaction with ABTS as a substrate at $420 \mathrm{~nm}$ with reported procedures [52]. Lac activity was calculated employing Lambert-Beer law, the extinction coefficient $(\varepsilon)$ is $36000 \mathrm{M}^{-1} \mathrm{~cm}^{-1}$. The manganese peroxidase $(\mathrm{MnP})$ activity was measured by monitoring the oxidation of 2,6-dimethoxyphenol (2,6-DMP) as the substrate at $470 \mathrm{~nm}\left(\varepsilon_{470}=49,600 \mathrm{M}^{-1} \mathrm{~cm}^{-1}\right)$ [53]. The 
enzymatic activity was calculated with the UV absorption data according to reported methods [54].

\section{Determination of degradation rates}

Degradation rates of lignin by employing a single and a mixture of fungi were determined by the Laboratory Analysis Protocol (LAP) from the National Renewable Energy Laboratory (NREL) [55]. In this method, the contents of acid-soluble and acid insoluble lignin need to be determined separately [56]. Before determining the lignin content, the lignin in the biomass needs to be dissolved under alkaline conditions and precipitated under acidic conditions [57]. The lignin degradation rates were determined combing the acid insoluble and soluble portions of the sample according to the NREL protocol.

\section{Scanning electron microscope (SEM)}

The changes of morphology and structures were observed by SEM. The samples were prepared by centrifuging the culture solution at the end of cultivation at $8000 \mathrm{rpm}$ for $10 \mathrm{~min}$ and the precipitate was collected and lyophilized for $48 \mathrm{~h}$ to achieve a constant weight. Samples were coated with gold powder by a spray meter beforehand [41]. The samples were subjected to analysis by a TESCAN MALA3 LMH, Czech Republic.

\section{Secondary-ion mass spectrometry (SIMS)}

Lignin samples after cultivation were centrifuged for $10 \mathrm{~min}$ at $8000 \mathrm{rpm}$. The precipitate was placed at $-80^{\circ} \mathrm{C}$ for $24 \mathrm{~h}$ and then freeze dried under reduced pressure. The samples were then grinded into powders. The fungi cells were removed by adjusting the $\mathrm{pH}$ to 12 by addition of $\mathrm{NaOH}\left(2 \mathrm{~mol} \mathrm{~L}^{-1}\right)$ and placed at $30^{\circ} \mathrm{C}$ water bath for $24 \mathrm{~h}$, then centrifuged at $5000 \mathrm{rpm}$, room temperature for $5 \mathrm{~min}$. The supernatant was transferred and $\mathrm{pH}$ was adjusted to 3 by addition of $\mathrm{H}_{2} \mathrm{SO}_{4}\left(2 \mathrm{~mol} \mathrm{~L}^{-1}\right)$, then placed in $30^{\circ} \mathrm{C}$ water bath for $24 \mathrm{~h}$. The final sample was obtained by centrifuging at $5000 \mathrm{rpm}$, room temperature and freeze dried again under reduced pressure for $24 \mathrm{~h}$. The lignin sample without fungi was pressurized into a thin layer with a thickness of approximated $5 \mathrm{~mm}$. The top surface $\sim 100 \mathrm{~nm}$ of the sample was subjected to SIMS measurement with a novel gas cluster ion beam (GCIB) and J105 3D Chemical Imager (Ionoptika, UK) with published procedures [58].

\section{Heteronuclear single quantum coherence (2D-HSQC) NMR}

Lignin cultivation samples were pretreated by centrifugation, lyophilization, alkaline dissolution, centrifugation, acid precipitation and re-lyophilization. Subsequently $50 \mathrm{mg}$ sample was dissolved in $0.5 \mathrm{~mL}$ DMSO-D6 and the solvent peak was used as a reference. 2D-HSQC measurements were performed at
$25{ }^{\circ} \mathrm{C}$ with a Bruker AVAVCE III HD $700 \mathrm{MHz}$ spectrometer and the Bruker standard pulse program was used [59]. HSQC cross-signals were analyzed and assigned by comparison with published results.

\section{Gas chromatography-mass spectrometry (GC-MS)}

Samples for GC-MS analysis were taken at $50 \mathrm{~mL}$ aliquots from the cultivation culture and centrifuged at $8,000 \mathrm{rpm}$ for $10 \mathrm{~min}$ to remove the cells. The centrifugation condition was and the $\mathrm{pH}$ was adjusted to approximately 2 by addition of $6 \mathrm{~mol} \mathrm{~L}^{-1} \mathrm{HCl}$ to the centrifuged supernatant. Subsequently, the mixture was derivatized according to reported procedures [60].The derivatized sample $(1 \mu \mathrm{L})$ was injected into the GC-MS (Thermo Fisher Scientific Trace ISQ, America). The capillary column used was HP-5 with Helium as the carrier gas, and the solvent delay time was $180 \mathrm{~s}$. The injection temperature, ion source temperature, and transfer line temperature were 280,250 , and $200{ }^{\circ} \mathrm{C}$, respectively. The column temperature program was set as follows: first heated from room temperature to $50{ }^{\circ} \mathrm{C}$ for $5 \mathrm{~min}$, then the temperature was raised at $10{ }^{\circ} \mathrm{C}$ $\min ^{-1}$ acceleration rate to $300{ }^{\circ} \mathrm{C}$, then maintained for $5 \mathrm{~min}$. The ionization mass spectrum in the range of $30-550 \mathrm{~m} / \mathrm{z}$ was recorded in Full Scan mode and $70 \mathrm{eV}$ electron energy, and the results were compared with standard mass spectrometry databases to determine the products after lignin degradation [61].

\section{Abbreviations \\ Lac: Laccase; MnP: Manganese peroxidase; SEM: Scanning electron micro- scope; SIMS: Secondary-ion mass spectrometry; HSQC: Heteronuclear single quantum coherence; GC-MS: Gas chromatography-mass spectrometry; LiP: Lignin peroxidase; WRF: White rot fungi; $\beta$-KA: $\beta$-Ketoadipate; ROS: Reactive oxidative species; $\mathrm{S}^{\prime}$ : Ca-oxidized syringyl; $\mathrm{H}$ : $p$-Hydroxyphenyl; G: Guaiacyl; S: Syringyl; OMe: Methoxy; Aү: ß-O-4 Structures; PDA: Potato dextrose agar; 2,6- DMP: 2,6-Dimethoxyphenol; GCIB: Gas cluster ion beam.}

\section{Acknowledgements}

We would like to show our appreciation to Dr. Huimin Tong and the Instrument Analysis Center of Xi'an Jiaotong University for helping with analysis.

\section{Authors' contributions}

TWC performed the cultures and drafted this manuscript. BY advised on the experiment design and revised the manuscript. HWG carried out the HSQC and analyzed results. HT carried out the SIMS and analyzed the results. WMW helped the experiment and prepared the manuscript. YQM advised on the design and revised the manuscript. CZL helped the experiment design and revised the manuscript. QF designed the experiments. All authors read and approved the final manuscript.

\section{Funding}

This work was supported by the National Key R\&D Programs of China (2020YFD1100500), National Natural Science Foundation of China (Nos. $21878288,21690083)$, and the Postdoctoral Science Foundation of Shaanxi Province (No. 2017BSHEDZZ58).

Availability of data and materials Not applicable. 


\section{Declarations}

Ethical approval and consent to participate

Not applicable.

\section{Consent for publication}

Not applicable.

\section{Competing interests}

The authors declare no competing interests.

\section{Author details}

'School of Chemical Engineering and Technology, Xi'an Jiaotong University, Xi'an 710049, China. ${ }^{2}$ CAS Key Laboratory of Science and Technology On Applied Catalysis, Dalian Institute of Chemical Physics, Chinese Academy of Sciences, 457 Zhongshan Road, Dalian 116023, People's Republic of China. ${ }^{3}$ Department of Chemistry, Pennsylvania State University, 215 Chemistry Bldg., University Park, PA 16802, USA. ${ }^{4}$ Shaanxi Key Laboratory of Energy Chemical Process Intensification, Xi'an Jiaotong University, Xi'an 710049, People's Republic of China.

Received: 16 April 2021 Accepted: 7 July 2021

Published online: 23 July 2021

\section{References}

1. Michael EH, Shi-You D, David KJ, William SA, Mark RN, John WB, Thomas DF. Biomass recalcitrance: engineering plants and enzymes for biofuels production. Science. 2007;315(5813):804-7.

2. Chen Z, Wan C. Biological valorization strategies for converting lignin into fuels and chemicals. Renew Sustain Energy Rev. 2017;73:610-21.

3. Asina F, Brzonova I, Kozliak E, Kubátová A, Ji Y. Microbial treatment of industrial lignin: successes, problems and challenges. Renew Sust Energy Rev. 2017:8:65.

4. Li C, Zhao X, Wang A, Huber GW, Zhang T. Catalytic transformation of lignin for the production of chemicals and fuels. Chem Rev. 2015;115:11559-624.

5. Liao Y, Koelewijn SF, Den Bossche GV, Van Aelst J, Den Bosch SV, Renders T, Navare K, Nicolai T, Van Aelst K, Maesen M. A sustainable wood biorefinery for low-carbon footprint chemicals production. Science. 2020;367:1385-90.

6. Weng C, Peng X, Han Y. Depolymerization and conversion of lignin to value-added bioproducts by microbial and enzymatic catalysis. Biotechnol Biofuels. 2021;14:84.

7. Pollegioni L, Tonin F, Rosini E. Lignin-degrading enzymes. FEBS J. 2015;282:1190-213

8. Munk L, Sitarz AK, Kalyani DC, Mikkelsen JD, Meyer AS. Can laccases catalyze bond cleavage in lignin? Biotechnol Adv. 2015;33:13-24.

9. Bugg TDH, Rahmanpour R. Enzymatic conversion of lignin into renewable chemicals. Curr Opin Chem Biol. 2015;29:10-7.

10. Ahmad M, Taylor CR, Pink D, Burton K, Eastwood D, Bending GD, Bugg TD. Development of novel assays for lignin degradation: comparative analysis of bacterial and fungal lignin degraders. Molecular Biosysttems. 2010;6:815-21.

11. Mnich E, Vanholme R, Oyarce P, Liu S, Lu F, Goeminne G, Jorgensen B, Motawie MS, Boerjan W, Ralph J, et al. Degradation of lignin beta-aryl ether units in Arabidopsis thaliana expressing LigD, LigF and LigG from Sphingomonas paucimobilis SYK-6. Plant Biotechnol Journal. 2017;15:581-93

12. Dashtban M, Schraft H, Syed TA, Qin W. Fungal biodegradation and enzymatic modification of lignin. Int J Biochem Mol Biol. 2010;1:36.

13. Thanh Mai Pham L, Eom MH, Kim YH. Inactivating effect of phenolic unit structures on the biodegradation of lignin by lignin peroxidase from Phanerochaete chrysosporium. Enzyme and Microbial Technology. 2014; 61-62: 48-54.

14. Reid ID. Fate of residual lignin during delignification of kraft pulp by Trametes versicolor. Appl Environ Microbiol. 1998:64:2117-25.
15. Xu X, Xu Z, Shi S, Lin M. Lignocellulose degradation patterns, structural changes, and enzyme secretion by Inonotus obliquus on straw biomass under submerged fermentation. Biores Technol. 2017;241:415-23.

16. Wells T, Ragauskas AJ. Biotechnological opportunities with the B-ketoadipate pathway. Trends Biotechnol. 2012;30:155.

17. Asina FNU, Brzonova I, Kozliak E, Kubátová A, Ji Y. Microbial treatment of industrial lignin: Successes, problems and challenges. Renew Sustain Energy Rev. 2017;77:1179-205.

18. Asina F, Brzonova I, Voeller K, Kozliak E, Kubatova A, Yao B, Ji Y. Biodegradation of lignin by fungi, bacteria and laccases. Biores Technol. 2016;220:414-24

19. Jaouani A, Sayadi S, Vanthournhout M, Penninckx MJ. Potent fungi for decolourisation of olive oil mill wastewaters. Enzyme Microb Technol. 2003:33:802-9.

20. Goud JVS, Bindu NS, Samatha B, Prasad MR, Charya MAS. Lignolytic enzyme activities of wood decaying fungi from Andhra Pradesh. J Indian Acad Wood Sci. 2011;8:26

21. Snajdr J, Baldrian P. Temperature affects the production, activity and stability of ligninolytic enzymes in Pleurotus ostreatus and Trametes versicolor. Folia Microbiol. 2007:52:498-502.

22. Tortella GR, Rubilar O, Gianfreda L, Valenzuela E, Diez MC. Enzymatic characterization of Chilean native wood-rotting fungi for potential use in the bioremediation of polluted environments with chlorophenols. World J Microbiol Biotechnol. 2008;24:2805.

23. Wong DWS. Structure and Action Mechanism of Ligninolytic Enzymes. Appl Biochem Biotechnol. 2009;157:174-209.

24. Sperandio GB, Ferreira Filho EX. Fungal co-cultures in the lignocellulosic biorefinery context: a review. Int Biodeterior Biodegradation. 2019;142:109-23

25. Klammsteiner T, Turan V, Juárez MF, Oberegger S, Insam H. Suitability of black soldier fly frass as soil amendment and implication for organic waste hygienization. Agronomy. 2020;10:1578.

26. Turan V, Schröder P, Bilen S, Insam H, Juárez MF-D. Co-inoculation effect of Rhizobium and Achillea millefolium L. oil extracts on growth of common bean (Phaseolus vulgaris L.) and soil microbial-chemical properties. Sci Rep. 2019;9(1):15178.

27. Rasool B, Ramzani PMA, Zubair M, Khan MA, Lewińska K, Turan V, Karczewska A, Khan SA, Farhad M, Tauqeer HM. Impacts of oxalic acid-activated phosphate rock and root-induced changes on $\mathrm{Pb}$ bioavailability in the rhizosphere and its distribution in mung bean plant. Environ Pollut. 2021;280:116903.

28. Khan MA, Ramzani PMA, Zubair M, Rasool B, Khan MK, Ahmed A, Khan SA Turan $V$, lqbal M. Associative effects of lignin-derived biochar and arbuscular mycorrhizal fungi applied to soil polluted from $\mathrm{Pb}$-acid batteries effluents on barley grain safety. Sci Total Environ. 2020;710:136294.

29. Chi Y, Hatakka A, Maijala P. Can co-culturing of two white-rot fungi increase lignin degradation and the production of lignin-degrading enzymes? Int Biodeterior Biodegrad. 2007;59:32-9.

30. Luo F, Zhong Z, Liu L, Igarashi Y, Xie D, Li N. Metabolomic differential analysis of interspecific interactions among white rot fungi Trametes versicolor Dichomitus squalens and Pleurotus ostreatus. Sci Rep. 2017:7:5265-5265.

31. Ferreira Gregorio AP, Da Silva IR, Sedarati MR, Hedger JN. Changes in production of lignin degrading enzymes during interactions between mycelia of the tropical decomposer basidiomycetes Marasmiellus troyanus and Marasmius pallescens. Mycol Res. 2006;110:161-8.

32. Zhang H, Hong $Y Z$, Xiao $Y Z$, Yuan J, Tu XM, Zhang XQ. Efficient production of laccases by Trametes sp. AH28-2 in cocultivation with a Trichoderma strain. Appl Microbiol Biotechnol. 2006;73:89-94.

33. Kuhar F, Castiglia V, Levin L. Enhancement of laccase production and malachite green decolorization by co-culturing Ganoderma lucidum and Trametes versicolor in solid-state fermentation. Int Biodeterior Biodegradation. 2015:104:238-43.

34. Qi HC, Krügener S, Hirth T, Rupp S, Zibek S. Co-cultured production of lignin-modifying enzymes with white-rot fungi. Appl Biochem Biotechnol. 2011;165:700-18.

35. Silar P. Peroxide accumulation and cell death in filamentous fungi induced by contact with a contestant. Mycol Res. 2005;109:137-49.

36. Karpe AV, Dhamale WV, Morrison PD, Beale DJ, Harding IH, Palombo EA. Winery biomass waste degradation by sequential sonication and mixed fungal enzyme treatments. Fungal Genet Biol. 2017;102:22-30. 
37. Wang H, Peng L, Ding Z, Wu J, Shi G. Stimulated laccase production of Pleurotus ferulae JM301 fungus by Rhodotorula mucilaginosa yeast in co-culture. Process Biochem. 2015;50:901-5.

38. Yang R, Meng D, Hu X, Ni Y, Li Q. Saccharification of pumpkin residues by coculturing of Trichoderma reesei RUT-C30 and Phanerochaete chrysosporium Burdsall with delayed inoculation timing. J Agric Food Chem. 2013;61:9192-9.

39. Knezevic A, Milovanovic I, Stajic M, Loncar N, Brceski I, Vukojevic J, Cilerdzic J. Lignin degradation by selected fungal species. Biores Technol. 2013;138:117-23.

40. Fang X, Li Q, Lin Y, Lin X, Dai Y, Guo Z, Pan D. Screening of a microbial consortium for selective degradation of lignin from tree trimmings. Biores Technol. 2018;254:247-55.

41. Zhu D, Zhang P, Xie C, Zhang W, Sun J, Qian WJ, Yang B. Biodegradation of alkaline lignin by Bacillus ligniniphilus L1. Biotechnol Biofuels. 2017;10:44.

42. Meehnian $\mathrm{H}$, Jana AK, Jana MM. Pretreatment of cotton stalks by synergistic interaction of Daedalea flavida and Phlebia radiata in co-culture for improvement in delignification and saccharification. Int Biodeterior Biodegrad. 2017;117:68-77.

43. Mao JZ, Zhang X, Li MF, Xu F. Effect of biological pretreatment with whiterot fungus Trametes hirsuta C7784 on Lignin Structure in Carex meyeriana Kunth. Bioresources. 2013;8:45.

44. Zhao C, Xie S, Pu Y, Zhang R, Huang F, Ragauskas AJ, Yuan JS. Synergistic enzymatic and microbial lignin conversion. Green Chem. 2016;18:1306-12.

45. Zhu D, Si H, Zhang P, Geng A, Zhang W, Yang B, Qian W-J, Gabriel M, Sun J. Genomics and biochemistry investigation on the metabolic pathway of milled wood and alkali lignin-derived aromatic metabolites of Comamonas serinivorans SP-35. Biotechnol Biofuels. 2018;11:2014.

46. Abdelaziz OY, Brink DP, Prothmann J, Ravi K, Sun M, García-Hidalgo J, Sandahl M, Hulteberg CP, Turner C, Lidén G, Gorwa-Grauslund MF. Biological valorization of low molecular weight lignin. Biotechnol Adv. 2016;34:1318-46.

47. Mathews SL, Grunden AM, Pawlak J. Degradation of lignocellulose and lignin by Paenibacillus glucanolyticus. Int Biodeterior Biodegradation. 2016;110:79-86.

48. Chen Y, Chai L, Tang C, Yang Z, Zheng Y, Shi Y, Zhang H. Kraft lignin biodegradation by Novosphingobium sp. B-7 and analysis of the degradation process. Bioresour Technol. 2012;123:682-5.

49. Vardon DR, Franden MA, Johnson CW, Karp EM, Guarnieri MT, Linger JG, Salm MJ, Strathmann TJ, Beckham GT. Adipic acid production from lignin. Energy Environ Sci. 2015;8:617-28.

50. Hoshino F, Kajino T, Sugiyama H, Asami O, Takahashi H. Thermally stable and hydrogen peroxide tolerant manganese peroxidase (MnP) from Lenzites betulinus. FEBS Lett. 2002;530:249-52.
51. Zhang LH, Liu WX, Ge KS, Qian SJ. The optimization of manganese peroxidase production by Trametes versicolor. FEMS Microbiol Lett. 2005;32:98-102.

52. Ladeira Azar RIS, Morgan T, Dos Santos ACF, de Aquino XE, Ladisch MR, Guimaraes VM. Deactivation and activation of lignocellulose degrading enzymes in the presence of laccase. Enzyme Microb Technol. 2018;109:25-30.

53. Bermek H, Yazıcı H, Öztürk H, Tamerler C, Jung H, Li K, Brown KM, Ding H, Xu F. Purification and characterization of manganese peroxidase from wood-degrading fungus Trichophyton rubrum LSK-27. Enzyme Microb Technol. 2004;35:87-92.

54. Ramírez DA, Muñoz SV, Atehortua L, Michel FC. Effects of different wavelengths of light on lignin peroxidase production by the white-rot fungi Phanerochaete chrysosporium grown in submerged cultures. Biores Technol. 2010;101:9213-20.

55. Sluiter A, Hames B, Ruiz R, Scarlata C, Sluiter J, Templeton D, Crocker D. Determination of structural carbohydrates and lignin in biomass. Laboratory analytical procedure, NREL/TP-510-42618. 2012.

56. Chakar FS, Ragauskas AJ. Review of current and future softwood kraft lignin process chemistry. Ind Crops Prod. 2004;20:131-41.

57. Mahmood N, Yuan Z, Schmidt J, Xu C. Depolymerization of lignins and their applications for the preparation of polyols and rigid polyurethane foams: A review. Renew Sustain Energy Rev. 2016;60:317-29.

58. Tian H, Sparvero LJ, Blenkinsopp P, Amoscato AA, Watkins SC, Bayır H, Kagan VE, Winograd N. Secondary-ion mass spectrometry images cardiolipins and phosphatidylethanolamines at the subcellular level. Angew Chem Int Ed. 2019:58:3156-61.

59. Guo H, Zhang B, Qi Z, Li C, Ji J, Dai T, Wang A, Zhang T. Valorization of lignin to simple phenolic compounds over tungsten carbide: impact of lignin structure. Chemsuschem. 2017;10:523-32.

60. Raj A, Krishna Reddy MM, Chandra R. Identification of low molecular weight aromatic compounds by gas chromatography-mass spectrometry (GC-MS) from kraft lignin degradation by three Bacillus sp. Int Biodeterior Biodegrad. 2007:59:292-6.

61. Zhu D, Zhang P, Xie C, Zhang W, Sun J, Qian W-J, Yang B. Biodegradation of alkaline lignin by Bacillus ligniniphilus L1. Biotechnol Biofuels. 2017;10:44

\section{Publisher's Note}

Springer Nature remains neutral with regard to jurisdictional claims in published maps and institutional affiliations.
Ready to submit your research? Choose BMC and benefit from:

- fast, convenient online submission

- thorough peer review by experienced researchers in your field

- rapid publication on acceptance

- support for research data, including large and complex data types

- gold Open Access which fosters wider collaboration and increased citations

- maximum visibility for your research: over $100 \mathrm{M}$ website views per year

At BMC, research is always in progress.

Learn more biomedcentral.com/submissions 